\title{
Water quality modelling in tidal wetlands considering flooding and drying processes
}

\author{
M. L. C. Barros ${ }^{1}$, P. C. C. Rosman ${ }^{1}$ \& J. C. F. Telles ${ }^{2}$ \\ ${ }^{1}$ Oceanic Engineering Department - PENO/COPPE, \\ Federal University of Rio de Janeiro, Brazil \\ ${ }^{2}$ Civil Department - PEC/COPPE, \\ Federal University of Rio de Janeiro, Brazil
}

\begin{abstract}
Tidal wetlands are among the most important natural ecosystems and they play a variety of ecological functions. They are generally maintained by a flooding and drying tidal related cycle. Such cycles play an essential role in exchanging material over the estuarine and mangrove swamp complex. Therefore, the capacity to forecast the hydrodynamic processes and the water quality in such systems is required for the proper management of their environmental resources. In this paper, a water quality model applied to areas with flooding and drying processes is presented. The hydrodynamics is considered by using a $2 \mathrm{DH}$ model including a novel technique to represent the flooding and drying that considers flows through a "rough-porous medium" of the bed, called RPL (rough-porous layer). This technique bears similarities to the so-called marsh porosity method. The kinetic reaction processes of the water quality model were modified to include flooding and drying effects. In the model, the spatial and temporal variations of water quality variables are caused by physical-biological-chemical interactions under tidal mixing environment. The effectiveness of the water quality method coupled to the hydrodynamic model with flooding and drying is evaluated by modeling the complex Vitória Bay (Brazil) comprising extensive mangrove swamps.
\end{abstract}

Keywords: tidal wetland, flooding and drying processes, water quality. 


\section{Introduction}

Complex ecosystem as estuaries can include marine environments such as tidal wetland, mangrove swamps, along their inter-tidal shores. They are often dominated by complex channel networks and tidal floodplains, serving as a meeting point between land and sea. Further, they receive organic matter and inorganic nutrients from the land represent important systems where terrestrial nutrients and organic matter are subject to physical and biogeochemical processes before entering the coastal ocean. As a result, the water quality, ecology, and biodiversity of estuarine waters are under the threat of increasing anthropogenic nutrient inputs. Adverse impacts on estuarine ecosystem by human activities have been widely reported. Studies and management of the estuarine environments have gained more and more attention in recent decades, cf. $[1,2]$.

Notwithstanding the advances and applications of water quality models in shallow water regions, many of these models do not predict adequately tidal wetland. This is due to the occurrence of drying areas such as island and sandbanks at low tide. The addition of techniques that incorporate the hydrodynamic effects of flooding and drying adequately is essential, because this process plays an important role in nutrient exchange between the estuary and tidal wetland. This interaction may cause large change in the surface water quality in these areas $[3,4]$. Although there is various flooding and drying algorithms used by numerical models based on the shallow water equation. However, simulate the complex physical process of flooding and drying presents a nontrivial modeling challenge [5, 6].

In this paper a water quality model applied to areas with flooding and drying processes is presented. The hydrodynamics is considered by using a $2 \mathrm{DH}$ model coupled to a technique to represent the flooding and drying that considers flows through a "rough-porous medium" of the bed, called RPL (rough-porous layer), cf. [4, 8]. This method considers three media flow: above ground flow, transitional range flow and subsurface flow.

The difference this model to others in the literature is in considering the process of flooding and drying and the manner of calculation of kinetic process equations. Furthermore, the model become important tool to support research, management and assist the decision-making process on water quality of natural water bodies with flooding and drying cycle, because more realistic results can be obtained.

The remainder of this paper is organized as follows. In Section 2 the hydrodynamic and water quality governing equations, flooding-drying approach and kinetic processes are introduced. Section 3 presents numerical examples to illustrate the performance of the method. Concluding and final remarks are given in the last section. 


\section{Governing equations}

In this work a simplified version of the depth averaged module, 2DH, of the hydrodynamic model of SisBaHiA ${ }^{\circledR}$ (Base System for Environmental Hydrodynamic) is presented. The complete $3 \mathrm{D}$ and 2DH equations can be seen in [8]. As is well known, the vertically averaged shallow water equations are derived from the incompressible Navier-Stokes equations by assuming that the pressure is in hydrostatic balance and by averaging the equations along the vertical direction.

Let there be a computational domain with boundary $\Omega \subset R^{2}$. The shallow water equations can be written, using the conventional indicial notation (with $i, j$ $=1,2)$ as follows:

$$
\begin{gathered}
\frac{\partial H}{\partial t}+\frac{\partial H u_{i}}{\partial x_{i}}=0 \\
\frac{\partial u_{i}}{\partial t}+u_{j} \frac{\partial u_{i}}{\partial x_{j}}=- \\
+\frac{\partial \zeta}{\partial x_{i}}-g \frac{\partial\left(\rho / \rho_{r}\right)}{\partial x_{i}} \frac{H}{2}+\frac{1}{H}\left[\frac{\partial}{\partial x_{i}}\left(H \frac{\tau_{i j}^{T}}{\rho_{r}}\right)\right] \\
+\frac{1}{H}\left(\frac{\tau_{i}^{S}-\tau_{i}^{B}}{\rho_{r}}\right)+a_{i}
\end{gathered}
$$

where $u_{i}$ is the velocity component in i-direction, $z=\zeta(x, y, t)$ is the free surface elevation and $z=-h(x, y, t)$ the bottom position from a reference level, $H=\zeta+$ $h$ is the local instantaneous water column, and $\rho$ is the water density. The term $a_{i}$ stands for the Coriolis term, $\rho_{r}$ is a reference density, $g$ is the gravitational acceleration, $\tau^{S}$ and $\tau^{B}$ are surface and bottom stress vectors, respectively. The turbulent stress tensor, $\tau_{i j}^{T}$, is parameterized by filtering techniques; in a way similar to the Large Eddy Simulation approach with Gaussian filtering functions, see [9] for details.

The mass-balance equation for a non-conservative substance with advectiondiffusion terms and kinetic processes can be written as:

$$
\frac{\partial C_{m}}{\partial t}+u_{i} \frac{\partial C_{m}}{\partial x_{i}}=\frac{1}{H} \frac{\partial}{\partial x_{j}}\left(H\left[D_{i j} \delta_{j k}+\frac{\Lambda_{k}^{2}}{12}\left|\frac{\partial u_{j}}{\partial x_{k}}\right|\right] \frac{\partial C_{m}}{\partial x_{k}}\right)+F+\sum R_{c m}
$$

where $C_{m}$ is the concentration of the water quality variable, $D_{i j}$ is the turbulent diffusivity, $\delta_{j k}$ is Kronecker's delta, $k=1,2$, 3 where $k=3$ corresponding to time $t$, is the width of the Gaussian filter in the $x_{k}$ dimension and $\alpha_{k}$ is a homogeneous scaling parameter in the $x_{k}$ dimension, typically in the range of 0.25 to 2 . $F$ denotes the source or sink term and $\sum R_{C m}$ represents the kinetic processes. The following interpretation is valid for the index coefficient $C_{m}$ : $C_{N A}=$ ammonia nitrogen $\left(\mathrm{mg} \mathrm{N}^{-1}\right), C_{N}=$ nitrate nitrogen $\left(\mathrm{mg} \mathrm{N}^{-1}\right), C_{P I}=$ inorganic phosphorus $\left(\mathrm{mg} \mathrm{P} \mathrm{l}^{-1}\right), \mathrm{C}_{\mathrm{Chl}}=$ algal biomass $\left(\mathrm{mg} \mathrm{P} \mathrm{l}^{-1}\right.$ or $\left.\mathrm{mg} \mathrm{N} \mathrm{l}^{-1}\right), C_{B O D}=$ biochemical oxygen demand ( $\left.\mathrm{mg} \mathrm{O}_{2} \mathrm{l}^{-1}\right), C_{D O}=$ dissolved oxygen $\left(\mathrm{mg} \mathrm{O}_{2} \mathrm{l}^{-1}\right), C_{N O}=$ organic nitrogen $\left(\mathrm{mg} \mathrm{N} \mathrm{l}^{-1}\right), C_{P O}=$ organic phosphorus $\left(\mathrm{mg} \mathrm{P}^{-1}\right), \mathrm{C}_{\mathrm{Chl}}=$ chlorophyll a $\left(\mu \mathrm{g}^{-1}\right), C_{T}=$ temperature $\left({ }^{\circ} \mathrm{C}\right)$, and $C_{S}=$ salinity (psu). 
Furthermore, to obtain a well-posed problem appropriated boundary conditions have to be imposed along the boundary of the domain $\Gamma$, and an initial state needs to be provided.

The hydrodynamic model defined by equations (1) and (2) and the water quality model given by equation (3) are solved through SisBaHiA ${ }^{\circledR}$, cf. [8], using the finite-element method in space and the finite difference method in time.

\subsection{Flood-drying approach}

One of the major issues of the shallow-water governing equations in natural water bodies modeling is their inability to deal with drying and wetting areas, where the water depth can reach zero value. The aim of flooding and drying approach is to allow for the appearance and disappearance of these areas [10]. In the present work is used the RPL method, as introduced in [7].

The RPL method has similarities with the marsh porosity method considered in [11]. Both keep the same horizontal domain, and represent subsurface flow through a thin layer in areas where the fluid top layer is below ground level. But the RPL employs simpler ways of calculating the modified bathymetry and roughness within the subsurface flow layer.

This method considers that the water level surface can drop below ground level. The dry mesh nodes are not removed from the computational domain, but enter in a state of restricted subsurface flow. In the method there are three flow zones: above ground flow, transitional range flow, and subsurface flow. More details of RPL method can be found in $[7,8]$.

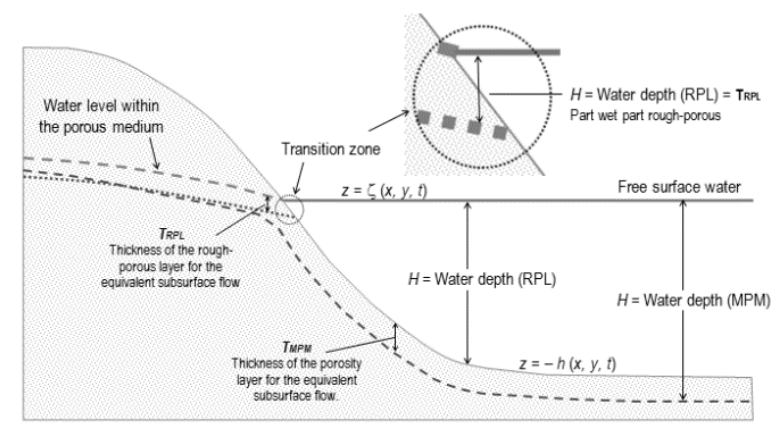

Figure 1: Approximate representation of change in flowing section of the proposed method. For the sake of visualization, the layer thicknesses are exaggerated.

\subsection{Kinetic processes}

The adopted water quality model (WQM) is based in a two-dimensional code of SisBaHiA ${ }^{\circledR}$ [8]. The model was adapted with inclusion of fluxes at the bottom resulting from flooding and drying processes. In the WQM, the parameter $F_{L}$, 
defines the liquid fraction of the water column, and determines if the flow occurs in wetted areas, transitional or porous regions:

$$
F_{L}=\frac{\max (\zeta+h ; 0)}{\left(\zeta+h_{R}\right)}
$$

where $\zeta$ is the free surface elevation, h the bottom elevation from a reference level, $h_{R}$ the bottom elevation from a reference level with porosity. $F_{L}=1$ indicates above ground flow, $0<F_{L}<1$ transition range flow, and $F_{L}=0$ subsurface flow.

Figure 2 presents schematically the interrelationships of the variables in the WQM.



Figure 2: $\quad$ Main interaction among of model water quality coupled flood and drying algorithm.

The scheme in Figure 2 shows interactions involving dissolved oxygen, nitrogen cycle and phytoplankton. Details of the kinetic reactions in the transformation processes for the above-mentioned substance can be found in [4]. The present work presents only details for the kinetic reactions of dissolved oxygen DO. Other parameters follow a similar reasoning. DO is one of the main variables in evaluating the water quality in a natural water body. As pointed out by many, e.g. [12], low DO concentration in the water body directly affects survivals of fishes, migrations of higher organisms, and alters ecological balances. The kinetic reactions for DO, referring to equation 3 , as affected by the drying and flooding processes are written as: 


$$
\begin{aligned}
\Sigma R_{D O}= & F_{L}\left\{k_{a} \Theta_{a}^{(T-20)}\left(C_{s}-C_{D O}\right)-K_{D} \Theta_{D}^{(T-20)}\left(\frac{C_{D O}}{K_{B O D}+C_{D O}}\right) C_{B D O}\right. \\
& -\frac{64}{14} K_{12} \Theta_{12}^{(T-20)}\left(\frac{C_{D O}}{K_{N I T}+C_{D O}}\right) C_{A N}+G_{P I}\left[\frac{32}{12}+\frac{48}{12}\left(1-P_{N H_{3}}\right)\right] C_{Z} \\
& \left.-\frac{32}{12} K_{1 R} \Theta_{1 R}^{(T-20)} C_{Z}-\frac{S O D}{H} \Theta_{S}^{(T-20)}\right\}
\end{aligned}
$$

\begin{tabular}{|c|c|c|c|}
\hline Coefficients & Description & Units & Value \\
\hline$G_{P I}$ & Algal biomass growth rate & day $^{-1}$ & 2.0 \\
\hline$K_{D}$ & De-oxygenation rate at $20^{\circ} \mathrm{C}$ & day $^{-1}$ & 0.2 \\
\hline$K_{B D O}$ & $\begin{array}{l}\text { Half-saturation constant for oxidation of } \\
\text { BOD }\end{array}$ & $\mathrm{mg} \mathrm{O}_{2} \mathrm{l}^{-1}$ & 0.5 \\
\hline$K_{\mathrm{NO}}$ & $\begin{array}{l}\text { Half-saturation constant for DO limitation } \\
\text { the denitrification process }\end{array}$ & $m g \mathrm{Nl}^{-1}$ & 0.1 \\
\hline$K_{a}$ & Re-aeration at $20{ }^{\circ} \mathrm{C}$ & day $^{-1}$ & 1.38 \\
\hline$K_{12}$ & Nitrification rate at $2{ }^{\circ} \mathrm{C}$ & day $^{-1}$ & 0.16 \\
\hline$K_{N I T}$ & $\begin{array}{l}\text { Half-saturation constant for DO limitation in } \\
\text { the nitrification process }\end{array}$ & $\mathrm{mg} \mathrm{O}_{2} \mathrm{l}^{-1}$ & 3.0 \\
\hline$K_{1 R}$ & Algal biomass respiration rate at $20^{\circ} \mathrm{C}$ & day $^{-1}$ & 0.12 \\
\hline$P_{N H 3}$ & Ammonia preference factor & & variable \\
\hline$S O D$ & Sediment oxygen demand & $\mathrm{g} \mathrm{mg}^{-1}$ day $^{-1}$ & 0.2 \\
\hline$\Theta_{D}, \Theta_{a \ldots}$ & $\begin{array}{l}\text { Temperature correction coefficient for de- } \\
\text { oxygenation, re-aeration, ... }\end{array}$ & - & \\
\hline
\end{tabular}

Table 1: $\quad$ Coefficients in the water quality model.

\section{Numerical result}

The following numerical simulations illustrate the performance of the WQM with to the RPL method for wetting and drying processes.

\subsection{Application to Vitória Bay}

The Vitória Bay on coast of the State of Espírito Santo (Brazil) shelters large ports, besides having one of the largest mangrove swamps located in an urban area in Brazil.

Due to the area's industrial development and demographic growth, the bay has suffered with the degradation of its waters, due to organic and industrial pollution. The present study concerns only organic pollution of Vitória Bay.

To simulate this estuary the main channels and the entire mangrove areas were included in the model. The Vitória Bay is a complex region with narrow channels and wide areas, with depths varying from $34 \mathrm{~m}$ to $-1 \mathrm{~m}$ in respect to mean sea level, MSL, at the Vitória Port. As shown in Figure 4 the mangrove areas top limit are indicated by $-1 \mathrm{~m}$ in the legend. The tides in the estuary have a range of up to $2 \mathrm{~m}$, cf. [13]. As the winds are usually mild and river flows are relatively small, the hydrodynamics of this complex region is mainly governed 


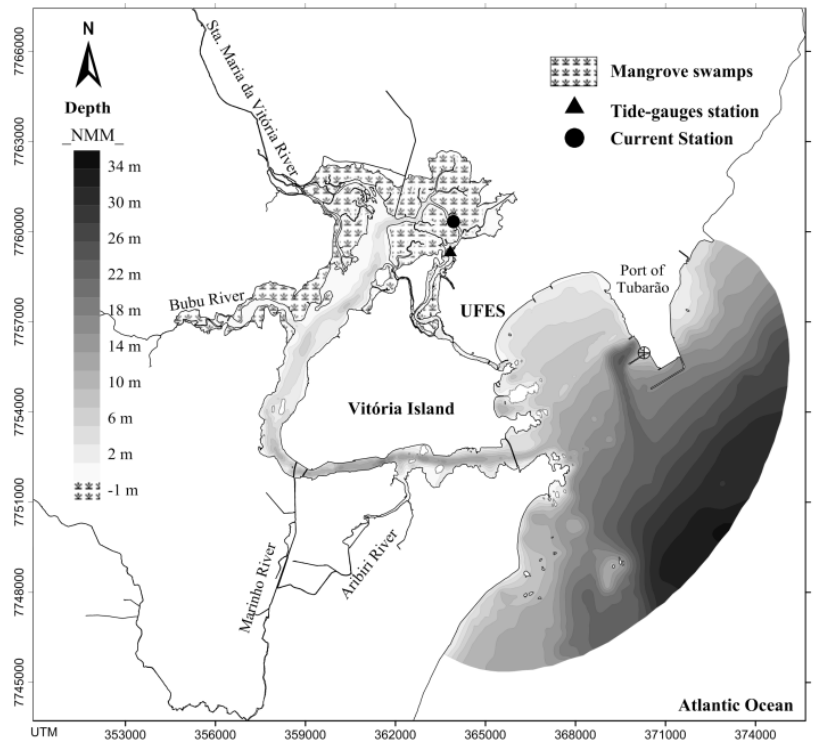

Figure 3: Map of Vitória Bay with bathymetry, showing the principal rivers, mangrove swamps and current station and tide-gauge station.

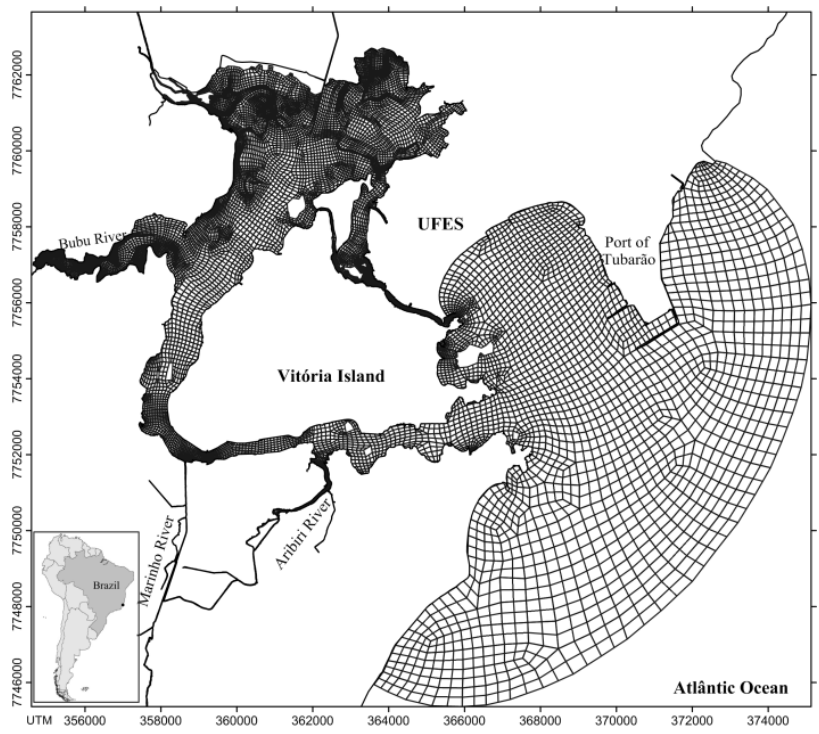

Figure 4: Vitória Bay modeling domain. Mesh of discrete domain model up of 4052 elements. 
by tidal effects. Due to the extensive mangrove areas, modeling the Vitória Bay hydrodynamics requires a consistent flooding and drying method. The main purpose of this simulation is to illustrate the capability of the RPL method to represent flooding and drying processes in a real case.

The mesh of the computational domain is presented in Figure 4, it has 4052 elements with Q2-Q1 interpolation and 17.886 nodes. The mesh is refined to capture the tidal channels within the mangrove swamps. No-slip conditions along the mangrove upper borders and impermeability conditions for other segments were set along the closed land boundaries. Open boundary conditions are regulated by tidal variations generated from data measured at Port of Tubarão, with proper phase lags. As initial conditions, velocities were set to zero and $\zeta$ to a uniform high water level.

For this test, the equivalent bottom roughness amplitude was $\varepsilon=0.04 \mathrm{~m}$ on mangrove areas and $0.03 \mathrm{~m}$ elsewhere. The parameters for the RPL method were $r=1.0$, and $T_{R P L}=0.25 \mathrm{~m}$. For the present test, the time step was $10 \mathrm{~s}$, giving a Courant number of up to 11 .

For the water quality model, typical literature values for the parameters and coefficients were applied. The field data for DO, BOD, temperature and salinity are listed in table 2, and the contributions of rivers Santa Maria and Bubu in Vitória Bay in table 3. As initial concentrations, $\mathrm{C}_{\mathrm{DO}}=7.5 \mathrm{mg} \mathrm{O}_{2} \mathrm{l}^{-1}, \mathrm{C}_{\mathrm{BOD}}=$ $3.0 \mathrm{mg} \mathrm{O}_{2} \mathrm{l}^{-1}, \mathrm{C}_{\mathrm{T}}=20^{\circ}, \mathrm{C}_{\mathrm{S}}=25.0 \mathrm{psu}$.

Table 2: $\quad$ Average discharges of main rivers into the Vitória Bay.

\begin{tabular}{lc}
\hline River & Discharge $\left(\mathrm{m}^{3} \mathrm{~s}^{-1}\right)$ \\
\hline Santa Maria da Vitoria & 26.0 \\
Bubu & 0.37 \\
\hline
\end{tabular}

Table 3: $\quad$ DO, BDO, salt concentration and temperature value in the rivers.

\begin{tabular}{lcccc}
\hline River & $\begin{array}{c}\mathrm{DO} \\
\left(\mathrm{mg} \mathrm{O}_{2} \mathrm{l}^{-1}\right)\end{array}$ & $\begin{array}{c}\mathrm{BOD} \\
\left(\mathrm{mg} \mathrm{O}_{2} \mathrm{l}^{-1}\right)\end{array}$ & $\begin{array}{c}\text { Temperature } \\
\left({ }^{\circ} \mathrm{C}\right)\end{array}$ & $\begin{array}{c}\text { Salinity } \\
(\mathrm{psu})\end{array}$ \\
\hline Santa M. da Vitoria & 7.6 & 1.76 & 24.5 & 2.09 \\
Bubu & 4.38 & 0.70 & 24.5 & 2.06 \\
\hline
\end{tabular}

Figure 5 shows the comparison on level oscillation results between observed data at Maria Ortiz station and numerical model was performed in a period of 30 days (11-out-2002/11-sep-2002). It is worth noting that the velocities comparison between model results and domain gathered data allude to the model competency in tidal currents simulation in the present area. Also, velocity evaluation on the model outcomes and observed data is show in Figure 6 .

The distributions of the DO concentration at ebb tide and flood tide are presented in Figure 7 and Figure 8. DO concentration was variable with value of more than $6 \mathrm{mg} \mathrm{O}$ l-1 in the inner and mouth of estuary and decreased to less than $5 \mathrm{mg} \mathrm{O}_{2} \mathrm{l}^{-1}$ in the upstream end of the estuary and extremely low over mangrove swamps. This spatial pattern was associated with differences in photosyntheses, nitrification, and SDO between the mouth of estuary and 
upstream region of the estuary. This implies that the low DO concentration in the Vitória Bay during ebb tide was caused by high SOD over the mangrove swamps.

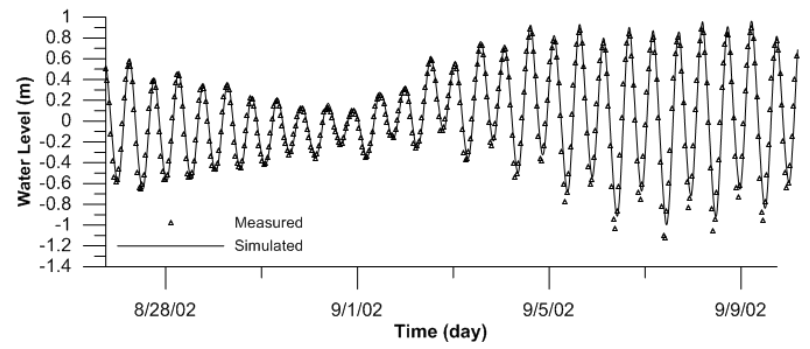

Figure 5: Curves of water level oscillation obtained from the numerical model and measured at Maria Ortiz in 30 day.

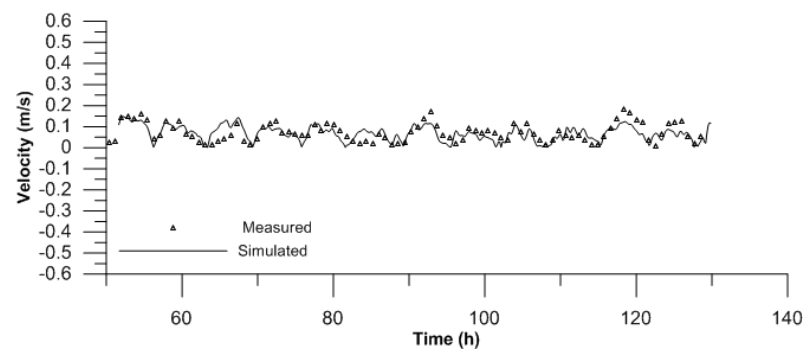

Figure 6: Curves of velocity obtained from the numerical model and measured at Maria Ortiz in 140 hours period.

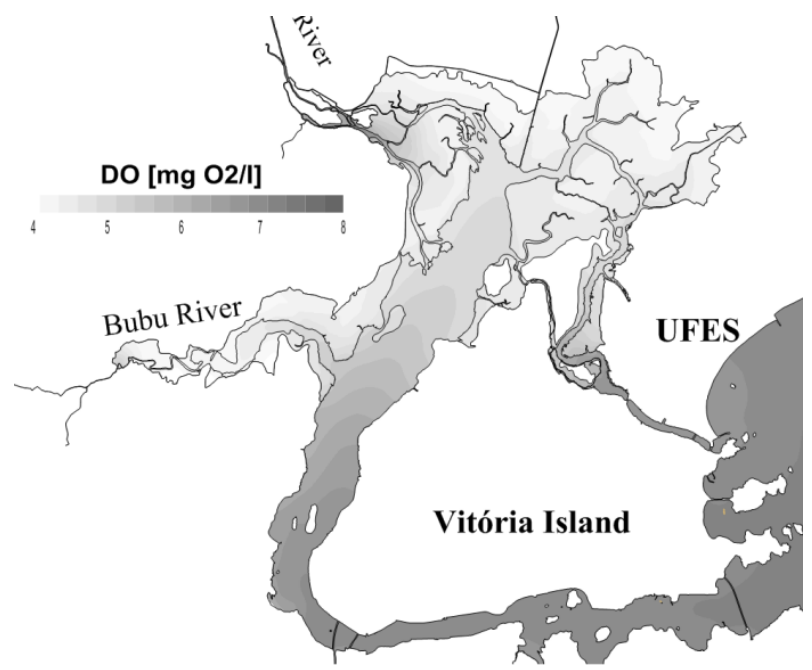

Figure 7: $\quad$ Dissolved oxygen concentration during flood tide. 


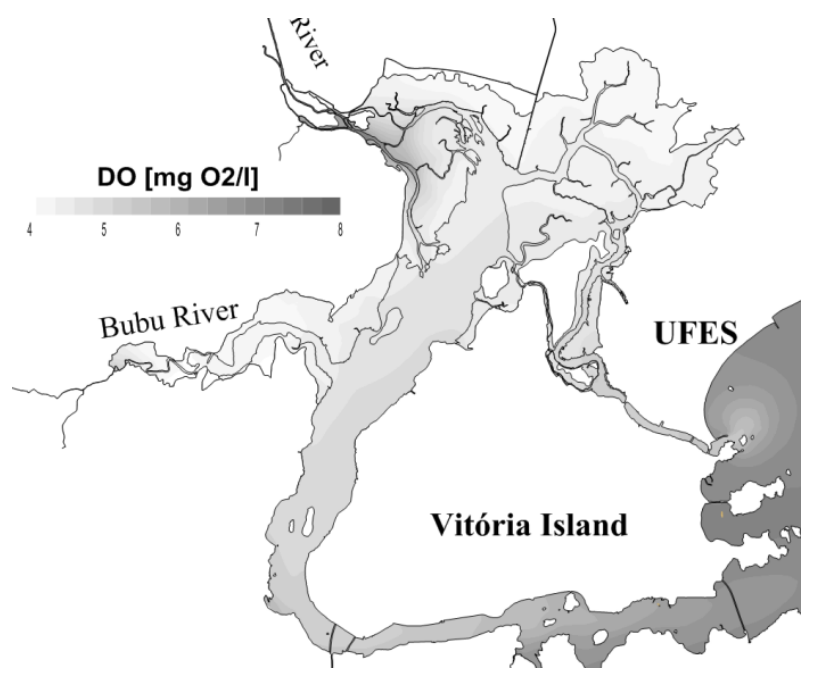

Figure 8: Dissolved oxygen concentration during at ebb tide.

\section{Conclusion}

Water quality in Vitória Bay was examined using a coupled water quality and hydrodynamic model with inclusion of flooding and drying processes to evaluate pollution by sewage effluent in the Vitória Bay.

Model studies suggest that water quality in this Bay was impacted by hydrodynamic and biogeochemical processes and their interactions. Low DO concentration in the Vitória Bay was due to the high SDO over the mangrove swamps and estuary channel area, which was a naturally occurring condition, rather than anthropogenic activities. The intertidal of the mangrove swamps acted as a main sink of DO the Vitória Bay.

\section{Acknowledgements}

MLCB benefited from a Research Scholarship from the Brazilian Ministry of Education through CNPq, identification number 160059/2012-7. Authors are grateful to Prof. Daniel Rigo of the Federal University of Espírito Santo for providing field data.

\section{References}

[1] Falconer, R. A., Lin, B. \& Kashefipour, S. M. Modeling water quality processes in estuaries (Chapter 12). Computational Fluid Dynamic: Application in environmental hydraulics, ed. P.D. Bates., S.N. Lane, \& R.I. Ferguson, John Wiley \& Sons, pp. 305-328, 2005. 
[2] Chen, W.B, Liu, W.C. \& Hsu, M.H. Water quality modeling in a tidal estuarine system using a three-dimensional model, Environmental Engineering Science, 28(6), pp., 2011.

[3] Junk, W.J., Bayley, P.B. \& Sparks, R.E. The flood pulse concept in riverfloodplains systems. Can. Spec. Publ. Fish. Aquat. Sci., 106, pp. 110-227, 1989.

[4] Barros, M.L.C. Modelagem hidrodinâmica e de qualidade de água em corpos de água com alagamento e secamento. Tese de D.Sc. Departamento de Engenharia Civil, COPPE/UFRJ, Rio de Janeiro, Brasil, 2012.

[5] Medeiros, S.C. \& Hangen, S. Review of wetting and drying algorithms for numerical tidal flow models. International journal for numerical methods in fluids. Online. http://dx.doi.org/10.1002/fld.3668, 2012.

[6] Bates, P.D., Development and testing of a sub-grid scale model for moving boundary hydrodynamic problems in shallow water. Hydrological Processes, 14, pp. 2073-2088, 2000.

[7] Barros, M.L.C., Rosman, P.C.C., Telles, J.C.F. \& Azevedo, J.P.S., Proc. $6^{\text {th }}$ Int. Conf. on Sustainable Water Resources Management, eds. C.A. Brebbia \& V. Popov, WIT Press: Riverside California, pp. 215-225, 2011.

[8] Rosman, P.C.C., (in Portuguese) Technical Reference of SisBaHiA, Universidade Federal do Rio de Janeiro, www.sisbahia.coppe.ufrj.br. 2012.

[9] Rosman, P.C.C., Modeling shallow water bodies via filtering techniques. Ph.D. Thesis, Department of Civil Engineering, Massachusetts Institute of Technology, 1987.

[10] Gourge, A., Coblen, R., Lambrechts, J., Kärnä, T., Legat, V. \& Deleersnijder, E., A flux-limiting wetting-drying method for finite-element shallow-water models, with application to the Sheldt Estuary. Advances in Water Resources, 32, pp.1726-1739, 2009.

[11] Nielsen, C. \& Apelt, C., Parameters effecting the performance of wetting and drying in two-dimensional finite element long wave hydrodynamic model. Journal of Hydraulic Engineering, 129(8), pp. 628-636, 2003.

[12] Zheng, L., Chen, C. \& Zhang, F., Development of water quality model in the Satilla River Estuary, Georgia, Ecological Modelling 178(2004), pp. 457-482, 2004.

[13] Rigo, D., Análise do escoamento em regiões estuarinas com manguezaisMedições e modelagem na Baía de Vitória, ES, D.SC. Tese de D.Sc. Departamento de Engenharia Costeira e Oceanográfica, COPPE/UFRJ, Rio de Janeiro, Brasil, 2004. 